\title{
Time estimates contribute to food handling decisions by rats: Implications for neural control of hoarding
}

\author{
IAN Q. WHISHAW \\ University of Lethbridge, Lethbridge, Alberta, Canada
}

\begin{abstract}
Laboratory rats carry (hoard) food from exposed areas to refuges for consumption or storage. This study was carried out to examine whether decisions to carry food are determined by food size or food handling time. When food size was varied, food handling behavior depended upon size in that small pellets of food were grasped by mouth and eaten directly (eat), intermediately sized pellets were eaten from the forepaws (sit), and large pieces of food were carried (carry) to a proximal refuge. When eating time was dissociated from size because of increased food hardness or the presentation of grains and nuts, which took a long time to eat relative to their size, behavior was determined by handling time. A second experiment involved a psychophysical adaptation procedure, in which responses to a series of small pellets were contrasted with responses to a series of large food pellets. The failure of the rats to show an adaptation effect for food carrying suggests that carrying decisions are based on an internal reference, possibly food handling time. Thus, these two lines of evidence suggest that handling time is the major stimulus feature that determines food handling behavior. These results support optimal foraging theory and are discussed in relation to ideas concerning the neural control of food carrying or hoarding.
\end{abstract}

Although it is known that some animals will carry (hoard) food to a refuge for consumption or storage, it is not known what stimulus features of an object are related to food carrying. Early studies by Bindra (1947, 1948) suggested that the value of an object as it relates to some motivational state is relevant to laboratory rats. Food-deprived animals carry food, and water-deprived animals carry water-soaked cotton pledges. A number of studies have emphasized the importance of food size. Ewer (1971) reported that Rattus rattus are more likely to carry larger pieces of cheese than smaller pieces of cheese, a result replicated in laboratory rats and other animals for a number of food substances (Covich, 1987; McNamara \& Whishaw, 1990; Phelps \& Roberts, 1989; Whishaw \& Oddie, 1989; Whishaw, Oddie, McNamara, Harris, \& Perry, 1990; Whishaw \& Tomie, 1989). On the other hand, Lima has reported that for both chickadees and gray squirrels, food handling time, or eating time, in combination with the distance to shelter determines whether food will be carried (Lima \& Valone, 1986; Lima, Valone, \& Caraco, 1985). Lima suggests that if food consumption time exceeds the time required for a return trip to shelter, an animal will carry food to

This research was supported by a grant from the Natural Sciences and Engineering Research Council of Canada. The author thanks Joanne Tomie and Pam Moro for assistance with the experiments. Stanley Coren of the University of British Columbia is thanked for his useful suggestions concerning the application of psychophysical procedures. Correspondence should be addressed to Ian $Q$. Whishaw, Department of Psychology, University of Lethbridge, Lethbridge, Alberta, TIK 3M4, Canada. the shelter for consumption, thus maximizing food intake and minimizing the risk of predation.

It is ordinarily difficult to determine whether food handling behavior is driven by food size or food handling time, because the two usually covary. The purpose in the present study was to investigate the relative influence of food size and food handling time on food carrying decisions. The behavioral paradigm has been described earlier (Whishaw \& Oddie, 1989; Whishaw et al., 1990; Whishaw \& Tomie, 1989). When rats are given food pellets of a number of different sizes, they display three different behaviors related to food size. They swallow small food pellets directly (eat), sit and eat intermediately sized food pellets from their paws (sit), and carry large food pellets to a refuge for consumption (carry). In the present experiment, the influence of size was examined by presenting animals with food pellets of a number of different sizes. The influence of handling time was examined by presenting similarly sized foods that would take longer to eat. These foods were either harder food pellets or a variety of natural foods. It was expected that this design would allow the contributions of food size and eating time to be dissociated.

In this study, the relevance of size as opposed to handling time was also examined, using adaptation procedures analogous to those employed in human psychophysical studies (Helson, 1959). In the absence of a reference, humans demonstrate that they are responding to stimulus size by adapting to context when given a series of stimuli. They judge the largest in a small series as being larger than it actually is and judge the smallest in a series of large stimuli as being smaller than it actually is. This method was used 
to determine whether rats are responding to the size of food stimuli. Rats were given either a range of smaller food pellets (low comparison series) or a range of larger food pellets (high comparison series), with the same food pellets (focal stimuli) being the largest pellets in the first series and the smallest pellets in the second series. The responses that the rats made with the food (eat, sit, carry) were viewed conceptually as categories in a category judgment scale. It was expected that if context was important, the rats would adapt to the comparison series such that they would conceptually overestimate the size of the focal stimuli in the low comparison series and underestimate the size of the focal stimuli in the high comparison series. This result would favor the idea that rats respond to stimulus size. If context effects did not emerge, the result would indicate that rats have an internal reference. This result would favor the idea that they make judgments on the basis of some other stimulus feature of the food, such as handling time.

\section{METHOD}

\section{Animals}

The experiments were conducted with 39 adult female rats (200-270 g) of the Long-Evans strain. The rats were maintained singly in an animal vivarium. Previous work has shown that in this task behavioral responses are similar in male and female rats, but fernale rats were used here because their size changes less than that of male rats (Whishaw et al., 1990). Lighting was 12:12 h, and all tests were conducted during the animals' light cycle. The animals were reduced to $90 \%$ body weight 14 days before the experiments began, and the deprivation schedule was maintained with once-aday supplementary feedings of premeasured quantities of food. Water was freely available.

\section{Food}

Rodent Chow food pellets (Bioserve, Frenchtown, NJ) were of two types and weighed $20,37,45,75,94,190,300,500,750$, and $1,000 \mathrm{mg}$. Throughout they are referred to as Sizes $1-10$. One pellet type (soft) was standard product Rodent Chow, and the second (hard) consisted of a special order of pellets that were given additional baking to make them harder, to increase consumption time. Four natural food products were used: pearl barley

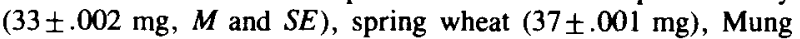
beans $(56 \pm .004 \mathrm{mg})$, and Azuki beans $(114 \pm .002 \mathrm{mg})$.

\section{Apparatus}

The hoarding box consisted of a goal cage and alley (Whishaw et al., 1990). The goal cage was a wire mesh cage similar to the cage in which the rats were housed. It was $21 \mathrm{~cm}$ wide, $25 \mathrm{~cm}$ high, and $19 \mathrm{~cm}$ long, with a metal roof, three metal sides, one Plexiglas side through which the animals could be observed and filmed, and a wire mesh floor. A 6-cm-wide, 7.5-cm-high door allowed access to the alley. The alley was $105 \mathrm{~cm}$ long, $25 \mathrm{~cm}$ wide, and $26 \mathrm{~cm}$ high. Food was given to the animals through a $1.5-\mathrm{cm}-$ diameter hole in the wall at the far end of the alley.

\section{Data Collection}

The behavior of the animals was recorded during each test, using an Apple IIGS microcomputer. A menu-driven program permitted selection of the number of trials, food pellets, food pellet sizes, and so forth. The microcomputer then indicated the trial number and food pellet size, which was determined according to a random number generator. Manually activated microswitches permitted the behavior of each rat, including movements and response speeds, to be entered into the computer. The following measures of behavior were recorded: (1) Eat-If an animal accepted the food by mouth and then chewed and swallowed the food directly, an "eat" was recorded. (2) Sit-If an animal accepted the food and then held it in its forepaws while eating it, a "sit" was recorded. (3) Carry-If an animal accepted the food and then carried it to the goalbox, a "carry" was recorded. (4) Carry time-the time taken to reach the goalbox with food. (5) Eating time-the time taken to eat a piece of food, either at the food source or after the goalbox had been entered. (6) Return time-the time taken to return to the food source for more food, after the previously presented piece of food was eaten.

\section{Training}

Lab chow tests. The animals were habituated to the test apparatus by being placed in it for $15 \mathrm{~min} /$ day, in groups of 3-4 animals for the first 7 days. Food pellets of different sizes were scattered on the floor at the end of the alley. Thereafter, the animals were placed in the apparatus singly, and food was presented by hand at the food aperture.

Natural foods. The rats used in the natural foods tests were first pretrained on soft food pellets as described above. Two separate experiments were performed. In the consecutive food presentation test, the rats were habituated in the test apparatus to the training food pellets or to one of the natural foods for 3 days. At the end of the habituation period, they were tested by being given 10 trials, with that food, for 3 successive days. They were then habituated to a second natural food and received another 3-day test, and so forth, until they had been tested on each kind of food. Each of the rats received the foods in a different order. In the concurrent presentation test, the rats were habituated to a mixture of the four kinds of natural food and to the soft food pellets and then tested with a mix of the soft food and the natural foods within each test session.

\section{Tests}

Three experiments were conducted.

Soft versus hard food pellets. Fifteen rats were used. One group ( $n=8$ ) was given the soft food pellets, and the second group $(n=7)$ received the hard food pellets. The rats were tested for 10 consecutive days, and on each day, they received 10 food pellets, one of each size.

Natural food. In the consecutive test, 6 rats were used. All rats received a 3-day test with the 10 soft food pellets. Then, after pretraining with one of the four natural foods, a rat received a 3day test in which only that food was presented. It was then pretrained to eat a different natural food and tested again. This procedure was repeated until each rat had been tested with each natural food. On each 3-day test, 10 food items were presented. In the concurrent test, 6 rats were used. They were pretrained to eat the soft food pellets and each of the natural foods. They then received 5 days of testing. On each day, 10 food items were presented, the four natural foods and soft food pellets Sizes 2-7.

Presentation context. Twelve rats were used. The rats were subdivided into two groups of 6 rats each. One group received the low comparison series, which was soft food pellets of pellets Sizes 1-7, during training and testing. The second group received the high comparison series, which was soft food pellets Sizes 4-10, during training and testing. At the completion of pretraining, the rats were given a test each day for 10 consecutive days. On each test, a rat received seven food pellets, one of each of the seven designated sizes.

\section{RESULTS}

\section{Soft versus Hard Food Pellets}

For both soft and hard food pellets, eating time and the incidence of food carrying increased with pellet size. In 
addition, the rats took longer to eat the hard food pellets than to eat the soft food pellets, and they also carried more hard food pellets than soft food pellets. These results are summarized in Figure 1.

Eating time. Analysis of eating time (Figure 1, top) gave significant group $[F(1,12)=23.5, p<.0001]$, pellet $[F(9,108)=265.5, p<.0001]$, and group $\times$ pellet $[F(81,972)=6.42, p<.001]$ effects. Pellet Sizes $1-3$ were usually eaten too quickly to obtain reliable eating measures. Newman-Keuls follow-up tests on time differences for pellet Sizes 4-10 indicated that for each pellet size the rats took longer to eat the hard pellets than the soft pellets.

Food carrying. Analysis of food carrying (Figure 1, bottom) gave significant group $[F(1,12)=48.07, p<$ $.0001]$, pellet $[F(9,108)=351.9, p<.0001]$, and group $\times$ pellet $[F(81,972)=1.45, p=.0078]$ effects. Followup tests showed that the rats carried more hard than soft food pellets of Sizes $4,5,6$, and 7 ( $p<.05$ ). There was no significant group effect in incidence of eats $[F(1,12)=$ $1.26, p=.28]$, nor was there a group $\times$ pellet interaction $[F(9,108)=.62, p=.77]$. Thus, the increase in the incidence of hoards of the hard pellets was accompanied by a concomitant reduction in the number of sits [group $\times$ pellet, $F(9,108)=4.81, p<.0001]$.

Response times. A number of behaviors were timed, including hoarding time (time to take food to the goal-
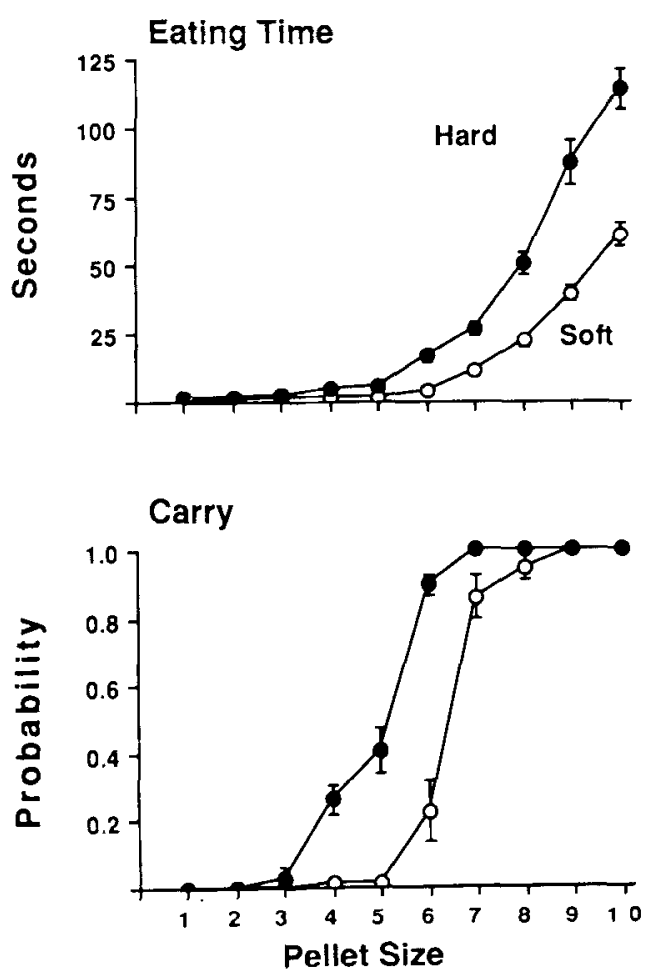

Figure 1. Comparison of eating time (top) and the incidence of hoarding (bottom) of hard and soft food pellets of similar size and weight. Note-the incidence of hoarding increases as the time taken to eat increases. box) and return time (time to return to the food source for another food pellet). (1) Carrying time. There was no group difference for carrying time $[F(1,13)=.17, p=$ .69], nor was there a group $\times$ pellet size interaction $[F(4,52)=1.57, p=.19]$. There was a significant effect of pellet size $[F(4,52)=15.5, p<.0001]$. Both groups of rats had latencies of about 2-3 sec to carry Size 6 food pellets and latencies between 1.3 and $1.4 \mathrm{sec}$ to carry Size 10 food pellets. (2) Return time. There was no group difference in time taken to return to the food source after a food pellet was eaten $[F(1,13)=.76, p=$ .39]. There was, however, a significant effect of pellet size $[F(4,52)=11.3, p<.001]$, as well as a significant interaction of pellet size $\times$ group $[F(4,52)=2.59, p=$ $.047]$. Both groups returned within about $5 \mathrm{sec}$ after eating Size 6 pellets and in about $7-10 \mathrm{sec}$ after eating Size 10 food pellets. The interaction was due to the rather slight tendency for the group receiving the hard food pellets to return more slowly after eating larger pellets.

\section{Natural Foods}

Consecutive tests. A summary of the results obtained in the experiment with consecutively presented natural foods and soft food pellets is given in Figure 2. The typical finding with the soft food pellets was that the rats directly ate the small pellets (Figure 2, top), sat with intermediately sized food pellets (Figure 2, middle), and carried the large food pellets (Figure 2, bottom). These behavioral responses can be contrasted with the responses made with natural foods, which are plotted as a function of size on the same figures. The rats displayed no eat responses with the natural foods, but there were differences as a function of food size in sit and carry responses. The response curves for sits and carries were shifted to the left, largely because the rats were much more likely to sit with and carry the natural foods than comparably sized food pellets.

For statistical analyses, each natural food was matched with a food pellet of comparable size-that is, Pellets 6 , 4, 3, and 2 were matched with Azuki beans, Mung beans, spring wheat, and pearl barley, respectively. There were significant effects for food type $\left[F_{\mathrm{s}}(1,7), p<.001\right]$, size $\left[F_{\mathrm{S}}(3,21), p<.001\right]$ and food type $\times$ size $\left[F_{\mathrm{S}}(3,21), p<\right.$ $.001]$ for each of the separate analyses of eat, sit, and hoard. Follow-up Newman-Keuls tests $(p<.05)$ indicated that all of the comparisons for individual paired items were significant.

Eating times were also compared for Food Pellets 2, 3,4 , and 6 and the four natural foods. Times for the food pellets were $1.06,1.72,2.45$, and $5.50 \mathrm{sec}$, and times for the natural foods of comparable size were $6.73,10.55$, 12.41 , and $28.21 \mathrm{sec}$. Thus, when the two types of food were compared, the difference was highly significant $[F(1,7)=56.4, p<.001]$.

Analyses were performed for carry and return times, and although there was a trend for response times to change relative to the time required to eat the natural foods, the differences were not significant. 

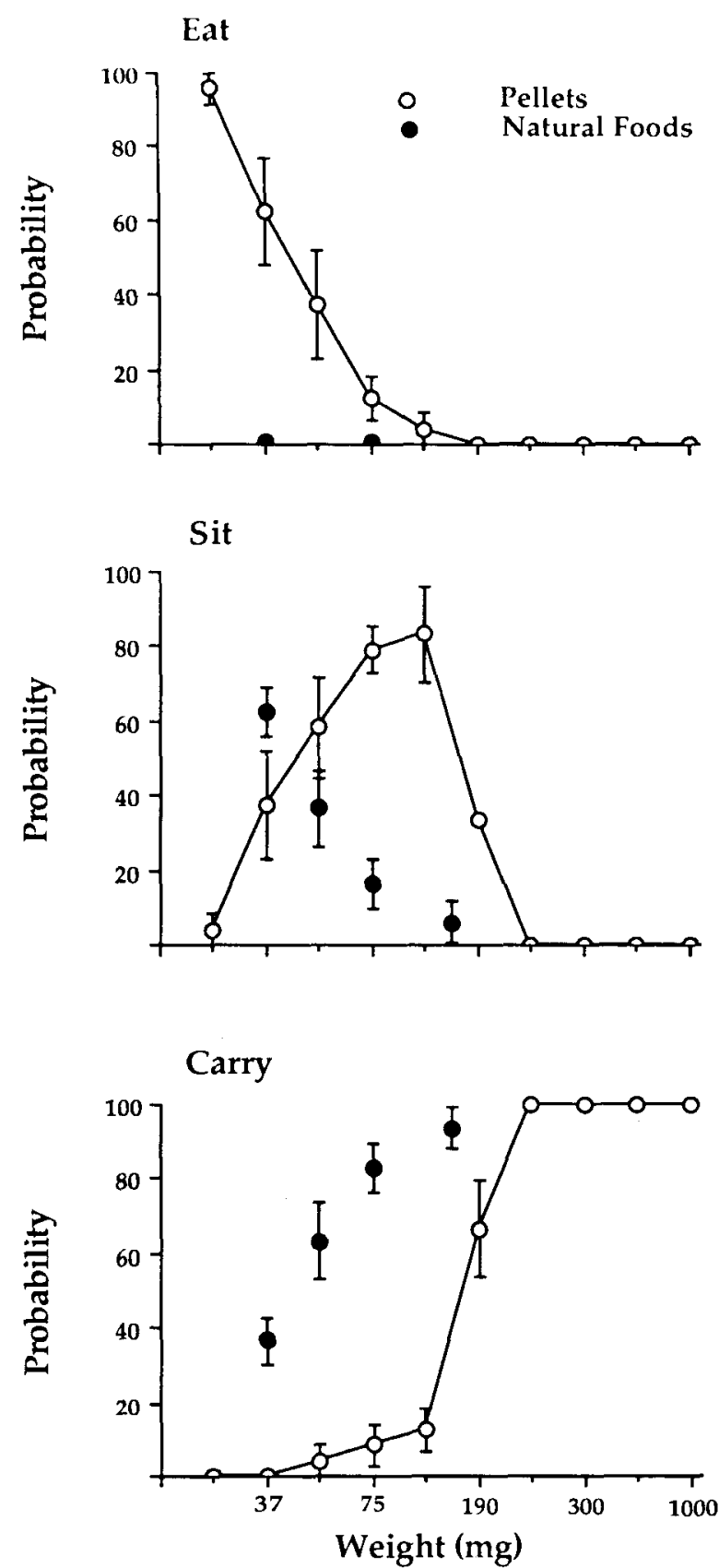

Figure 2. A comparison of the incidence of eats, sits, and hoards as related to object size for four types of natural food (barley, wheat, Mung beans, and Azuki beans, in that order) contrasted with a range of $\mathbf{1 0}$ differently sized standard laboratory soft food pellets. Note the lower incidence of eats and the higher incidence of sits and hoards for the natural foods as contrasted with food pellets of equivalent size.

Concurrent test. The results obtained on the concurrent test were essentially like those obtained on the consecutive test (above).

\section{Comparison of Hard, Soft, and Natural Foods}

When the food handling behavior was plotted against food size, the function depended on the kinds of food that the rats were given. To determine whether a better relationship could be obtained, food handling behavior was plotted against eating time. This produced very similar functions for each of the different foods. The relationship is shown in Figure 3. Figure 3 (top) illustrates the results obtained on the concurrent test. Here it can be seen that for a group of rats that received a mixture of soft food pellets (Sizes 2-7) and the four natural foods in a single test, eating time predicted the probability of food carrying for all foods. Figure 3 (bottom) illustrates the results obtained with different groups of rats that received soft pellets, hard pellets, or the natural foods. The data points from all groups fall on a similar curve. The curve also resembled that obtained when a single group of rats was given a mixture of food (Figure 3, top). Together, these results suggest that the major factor determining food handling decisions is anticipated eating time.
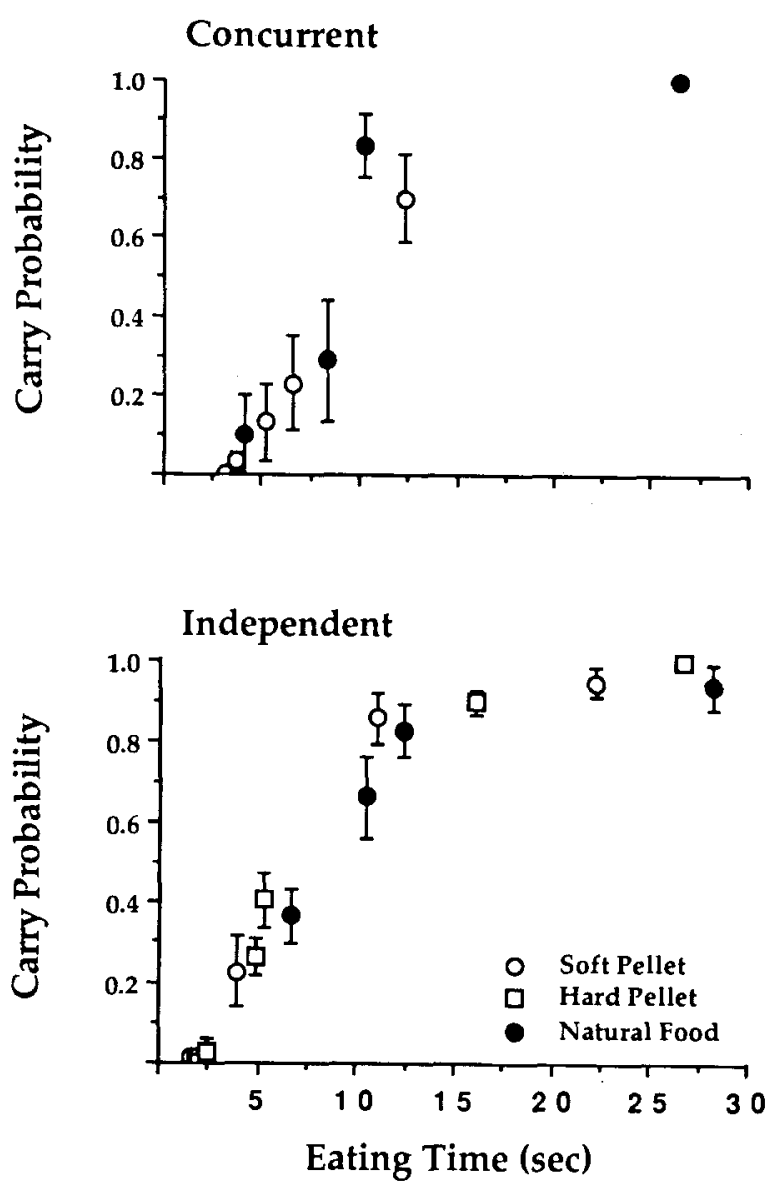

Figure 3. Relation between eating time and the probability of carrying food. Concurrent: Within each daily session, the rats received a mix of the four natural foods and soft food pellets, Sizes 2-7. Independent: Three different groups of rats were used. Rats received Sizes 1-10 soft pellets, but only results for sizes 2-7 are shown. Rats received Sizes $1-10$ hard pellets, but only results for Sizes $2-6$ are shown. Rats received each of the natural foods within separate consecutively administered tests. Note that for all groups in all test conditions there is a close relation between eating time and the probability of carrying food. 


\section{Context}

The main finding that emerged from the examination of the effect of presentation context on food handling behavior was that the incidence of sits or eats was influenced by context. The rats that received the low comparison series displayed more eats and fewer sits with the focal stimuli (Sizes 4-7) than did the rats that received the high comparison series. Context had no significant influence on the incidence of hoards.

The results are summarized in Figure 4. Separate analyses for eats, sits, and hoards were performed on the behavior of the rats with Pellets 4-7. For eats, there were significant group $[F(1,10)=21.25, p<.001]$, pellet $[F(3,30)=34.0, p<.0001]$, and group $\times$ pellet $[F(15,49), p<.0001]$ effects. Newman-Keuls followup tests showed that the rats given the small pellets more frequently displayed the eat behavior with Pellets 4 and 5 than did the rats given the large pellets. For sits, there were significant pellet $[F(3,30)=20.55, p<.0001]$ and group $\times$ pellet $[F(3,30)]$ effects. Follow-up tests showed that the rats given small food pellets sat significantly less frequently with Pellets 4 and 5 than did the group given large food pellets. There were no significant differences in hoards between the rats given the sequences of small food pellets and those given the sequences of large food pellets.

\section{DISCUSSION}

The relative contributions of food size and food handling time to food handling decisions were examined in these experiments. Within a single food type, in which size varied, rats apparently responded to size. When food type was varied, anticipated food handling time was shown to be the best predictor of food handling behavior. This conclusion was supported with a psychophysical adaptation experiment that suggested that the animals use an internal reference (possibly handling time) for making foodrelated behavioral decisions. The results support optimal foraging theory (Krebs \& McCleery, 1984), and they are relevant to questions conceming the neural control of food handling behavior.

Given a range of food pellet sizes, rats swallowed small food pellets, sat and ate intermediately sized food pellets from their paws, and carried large food pellets to a refuge. When the hardness of the food pellets was increased, thus increasing eating time, the relation between food handling behavior and food size changed. The rats sat with and carried smaller hard food items than was the case with the soft food pellets. Similarly, when the rats were given wheat, barley, or nuts-foods that were small enough to fall into the low end of the food pellet size range, but that were also hard and took considerably longer to eat than either the soft or the hard food pellets-handling responses were more closely related to food handling time than to food size. This suggests that the major factor determining food handling decisions is anticipated eating time.

An adaptation study, modeled on human psychophysical experiments (Helson, 1964), supported the idea that
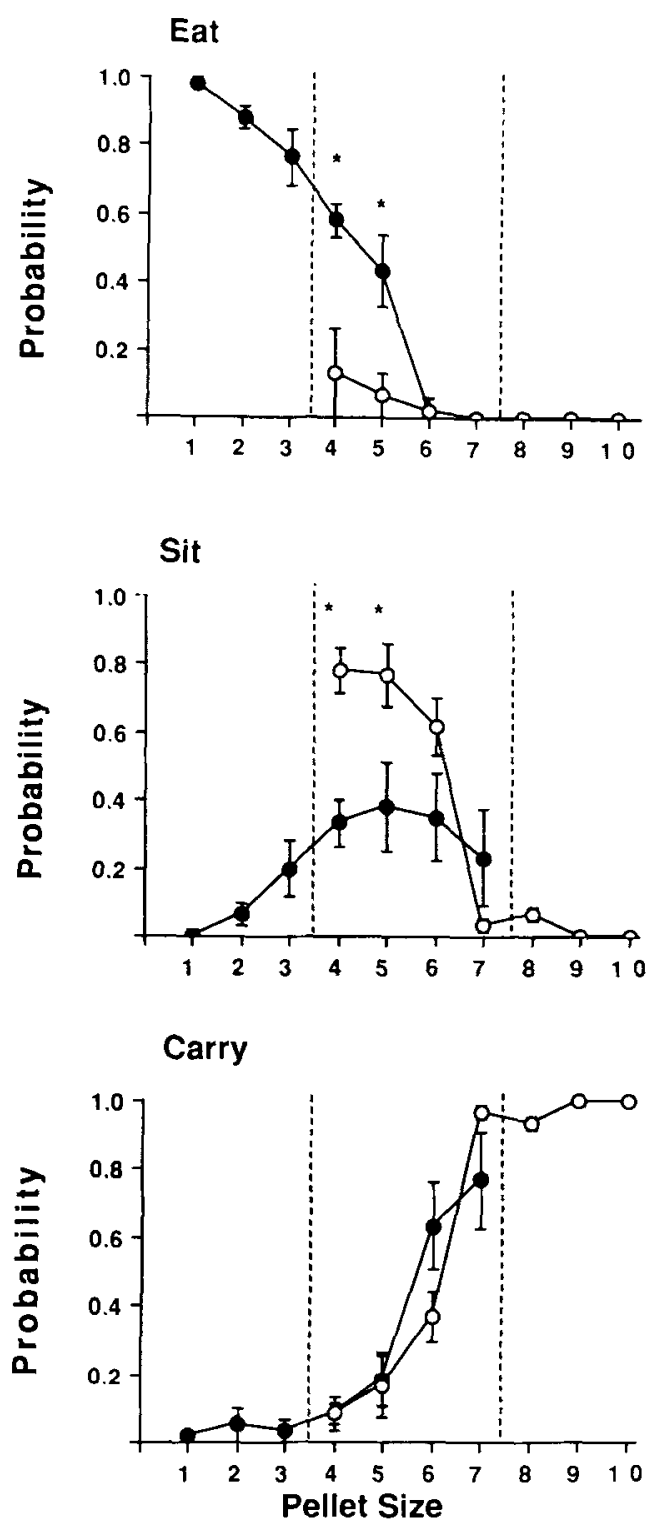

Figure 4. Effects of context on food handling behaviors (means and standard errors) for rats given small food pellets (Sizes 1-7) compared with rats given large food pellets (Sizes 4-10). Note that rats given the small pellets (solid circles) engaged in more eat and fewer sit behaviors than did rats given large food pellets (open circles), but that the context of food presentation did not affect the incidence of hoards. ${ }^{*} p<.05$, Newman-Keuls tests.

food carrying is determined by food handling time. Rats were given a series of small food pellets or a series of large food pellets, and their behavior with the pellets (eat, sit, carry) was used to form a category judgment scale. Food carrying responses were not affected by context. When humans make size-category judgments, they adapt to context, unless they are given some other reference. By analogy, the failure of the rats to adapt to context suggests that they are using another reference. This may be an internal reference and may very well be a time reference (see below). Interestingly, the incidence of eats and 
sits were influenced by the comparison series. This suggests that these behaviors, unlike carrying, may not be influenced by another reference.

From studies with chickadees and squirrels, Lima (Lima, 1985; Lima \& Valone, 1986) has advanced a foraging-efficiency-risk tradeoff model, consistent with optimal foraging theory, which predicts that food carrying is determined by both food size and the distance to a refuge. He argues that if return travel time exceeds eating time for a food item, then the food should be carried to a refuge in order to optimize food consumption and minimize risk of predation. The return trip time for the rats in the present study was about $4.5 \mathrm{sec}$. This is higher than the threshold of about $2 \mathrm{sec}$ for food carrying, but it is considerably lower than the asymptote $(>10 \mathrm{sec})$ at which all food is carried. Thus, the results generally support Lima's time hypothesis. As Lima notes, however, many other factors will contribute to an animal's behavior, including hunger, threat of predation, presence of conspecific competitors, and so forth, In addition, return trip time does not represent total elapsed time between foraging sorties (Whishaw \& Gorny, in press; Whishaw et al., 1990). The rats spend time in the home cage after eating and before leaving for another food pellet, and if this time is included along with travel time, total elapsed time for a return trip (excluding eating time) is about $12 \mathrm{sec}$. Since this represents time that a rat is away from a potential food source, but not eating food, it is likely that a rat will want to minimize this time loss. This in turn will raise the time threshold for food carrying. Nevertheless, despite the difficulty in specifying a precise time threshold for food carrying, the results of the present study do seem consistent with Lima's foraging-efficiency-risk model.

Both the present results and the results of Lima's experiments (Lima, 1985; Lima \& Valone, 1986) suggest that if travel distance is increased, the probability of carrying food, especially small pieces of food, should decrease. It is surprising, therefore, that Whishaw and Tomie (1989) failed to find an effect of distance on the carrying behavior of rats in tests in which travel distance was varied between 106 and $227 \mathrm{~cm}$. This may have occurred either because the same rats were tested at both distances or because the differences in distance were not large enough. In light of the present findings, this result should be reexamined, using distances that approximate those used in the natural foraging experiments. This experiment is currently in progress.

The present results show that decision making processes used by rats for food carrying are more complex than a simple stimulus-response judgment based on size. Depending on the presentation paradigm, they must use both size and food type to estimate anticipated eating time. This in turn suggests that they have to learn the identity and the qualitative features of their food to make decisions. What the limitations are on their mnemonic or cognitive abilities for dealing with a variety of food types and sizes is not known, and this question fell outside the major objectives in the present study. Nevertheless, it would be interesting to address this question by investigating how quickly an animal can acquire information about the properties of a food item and how many different items it can handle simultaneously

The results are relevant to the question of the neural control of hoarding. A number of studies suggest that damage or pharmacological disruption of limbic structures, including the frontal cortex (Kolb, 1974; Kolb \& Whishaw, 1981; Shipley \& Kolb, 1977; Whishaw \& Oddie, 1989), cingulate cortex (Stamm, 1953, 1954), hippocampus (McNamara \& Whishaw, 1990; Shipley \& Kolb, 1977; Wallace \& Tinger, 1972), ventral tegmentum, nucleus accumbens (Kelly \& Stinus, 1985; Stinus, Gaffori, Simon, \& LeMoal, 1978), and septum (Nanzen \& Bunnell, 1976; Shipley \& Kolb, 1977) can interfere with hoarding. Given that the structure of most hoarding tests is very simple, requiring only that a rat carry food from a lighted arena to a proximal visible refuge, no contemporary theory of limbic system function would predict that such a simple associative task requires limbic circuitry (O'Keefe \& Nadel, 1978; Sutherland \& Rudy, 1989). If it is recognized, however, that the animals are using processes that require knowledge of food item size and type, awareness of supplementary features of the foraging environment, and estimates of anticipated eating time, then the importance of limbic circuitry becomes recognizable. The associative demands of food handling decisions are then similar to the associative demands of behaviors that have been shown to be dependent on limbic circuitry (Squire, 1987; Sutherland \& Rudy, 1989).

\section{REFERENCES}

BindRA, D. (1947). Water hoarding in rats. Journal of Comparative \& Physiological Psychology, 40, 149-156.

BINDRA, D. (1948). What makes rats hoard? Journal of Comparative \& Physiological Psychology, 41, 379-402.

Covich, A. P. (1987). Optimal use of space by central place foragers: When and where to store surplus resources. In L. Green \& H. Kagel (Eds.), Advances in behavioural economics (pp. 249-294). Norwood, NJ: Ablex.

EWER, R. F. (1971). The biology and behavior of a free-living population of black rats (Rattus rattus). Animal Behaviour Monographs, 4 , 126-174.

Helson, H. (1959). Adaptation level theory. In S. Koch (Ed.), Psychology: A study of science (Vol. 1, pp. 565-621). New York: McGraw-Hill.

HeLSON, H. (1964). Adaptation level theory: An experimental and systematic approach to behavior. New York: Harper.

Kelley, A. E., \& Stinus, L. (1985). Disappearance of hoarding behavior after 6-hydroxydopamine lesions of the mesolimbic dopamine neurons and its reinstatement with L-Dopa. Behavioral Neuroscience, 99, 531-545.

KoLB, B. (1974). Prefrontal lesions alter eating and hoarding behavior in rats. Physiology \& Behavior, 12, 507-511.

Kolb, B., WhishaW, I. Q. (1981). Neonatal frontal lesions in the rat: Sparing of learned but not species-typical behavior in the presence of reduced brain weight and cortical thickness. Journal of Comparative \& Physiological Psychology, 95, 863-879 
KREBS, J. R., \& MCCLEERY, R. H. (1984). Optimization in behavioral ecology. In J. R. Krebs \& N. B. Davies (Eds.), Behavioral ecology (2nd ed., pp. 91-121). Sunderland, MA: Sinauer.

LimA, S. L. (1985). Maximizing feeding efficiency and minimizing time exposed to predators: A trade-off in the black-capped chickadee. Oecologia, 66, 60-67.

Lima, S. L., \& VALONE, T. J. (1986). Influence of predation risk on diet selection: A simple example in the grey squirrel. Animal Behaviour, 34, 536-544.

Lima, S. L., Valone, T. J., \& Caraco, T. (1985). Foraging-efficiencypredation-risk trade-off in the grey squirrel. Animal Behaviour, 33, 155-165

NANZEN, W. B., \& BunNell, B. N. (1976). Septal lesions and the recovery of function in the juvenile hamster. Physiology \& Behavior, 16 , 445-452.

McNamara, R. K. , \& Wishaw, I. Q. (1990). Blockade of hoarding in rats by diazepam: An analysis of the anxiety and object value hypotheses of hoarding. Psychopharmacology, 101, 214-221.

OKEEFE J., \& NADEL, L. (1978). The hippocampus as a cognitive map. New York: Oxford University Press.

Phelps, M. T., \& RoberTs, W. A. (1989). Central-place foraging by Rattus norvegicus on a radial maze. Journal of Comparative Psychology, 103, 326-338.

SHIPLEY, J. E., \& KoLB, B. (1977). Neural correlates of species-typical behavior in the Syrian golden hamster. Journal of Comparative \& Physiological Psychology, 91, 1056-1073.

SQuire, R. L. (1987). Memory and brain. New York: Oxford University Press.

Stamm, J. S. (1953). Effects of cortical lesions on established hoarding activity in rats. Joumal of Comparative \& Physiological Psychology, 46, 299-304.
Stamm, J. S. (1954). Control of hoarding activity in rats by median cerebral cortex. Journal of Comparative \& Physiological Psychology, 47, 21-27.

Stinus, L., Gaffori, O., Simon, H., \& LeMoal, M. (1978). Disappearance of hoarding and disorganization of eating behavior after ventral mesencephalic tegmental lesions in rats. Journal of Comparative \& Physiological Psychology, 92, 289-296.

SutherLAND, R. J., \& RUDY, J. W. (1989). Configural association theory: The role of the hippocampal formation in learning, memory, and amnesia. Psychobiology, 17, 129-144.

Wallace, R. J., Tinger, J. C. (1972). Effect of cortical and hippocampal lesions on hoarding behavior in the albino rat. Physiology \& Behavior, 8, 937-942.

WhISHAW, I. Q., \& GORNY, B. P. (in press). Postprandial scanning by the rat (Rattus norvegicus): The importance of eating time and an application of "warm-up" movements. Journal of Comparative Psychology.

Whishaw, I. Q., \& OdDIE, S. D. (1989). Qualitative and quantitative analyses of hoarding in medial frontal cortex rats using a new behavioral paradigm. Behavioural Brain Research, 33, 255-266.

Whishaw, I. Q., Oddie, S. D., McNamara, R. K., Harris, T. L., \& Perry, B. S. (1990). Psychophysical methods for study of sensorymotor behavior using a food carrying (hoarding) task in rodents. Journal of Neuroscience Methods, 32, 123-133.

Whishaw, I. Q., \& TomiE, J. (1989). Food-pellet size modifies the hoarding behavior of foraging rats. Psychobiology, 17, 93-101.

(Manuscript received February 5, 1990; revision accepted for publication June 1,1990 .) 